\title{
My Humble Opinion on the Reform of Educational Management Mode in the Big Data Age
}

\author{
Yu Lei \\ Zhonghuan Information College Tianjin University of Technology
}

Key words: large data age; educational management; model change

\begin{abstract}
The core problem of current educational management is the application of management tools and technology. Under the era of large data, in order to improve the quality of education management, it is necessary to apply modern means to education management, and to construct scientific and rational management platform in combination with educational management needs. This paper mainly analyzes the impact on education on the management of large data age, and builds a large data education management model which is based on its' structure, forming a road map that conforms to the characteristics of large data management. In order to achieve better development in the era of large data, it is necessary for educational administrators to meet the requirements of the times, update the management theory, methods and techniques to build a new educational management model to meet the current development.

Education management means that the education management personnel gives an optimal allocation of educational resources to achieve the coordinated operation of the process of the all activities. Under the era of large data, the educational management has changed. In order to promote the development of educational management, we must integrate new tools and technologies into education management, form a new educational management mode, and constantly tap external resources to meet the educational development goals.
\end{abstract}

\section{The Main Orientation of Education in the Big Data Age}

1.1 How to Achieve the Allocation of Educational Resources. Educational researchers have now recognized that the education system is the core of educational reform. From the core of the educational system, the educational system actually is the theoretical framework of resource allocation. In the era of large data, the amount of data is increasing, the state of educational resources began to change, scientific and rational allocation of resources has become the main content of educational managers. From the current development point of view, many of the current education management staffs still cannot do the job. At present, we already have a good development concept - achieve the optimal allocation of educational resources, but we still lack the technical means to achieve this theory, we cannot provide an effective solution to the problem.

1.2 The Value Orientation of Educational Evaluation. Assessment and management are closely linked, they have become the main tool for the realization of educational management. The assessment is the way to analyze and test the educational objectives, which reflects the current level of development of education, from that we can understand the problems in education, and provide a reference to the education reform. From the current educational evaluation of the practice point of view, the educational value orientation is still existing. The main reason for the long-term development of the examination-oriented education are that the traditional tools are deepening, which prompts many educational managers regards it as the reference data onto educational development, which leads to the separation of educational tools and values [1]. As we all know, data is the basis of educational assessment, but what is data? How to process of data? And other issues are still remained to be studied.

1.3 The Professional Level of Education Managers. The scientific educational management is in close contact with the professional capacity of the management of decision - makers themselves. In the information age, the professional capacity of many educational managers has been unable to meet the current development needs, especially the development of backward rural areas. In recent years, affected by many factors, leading to the educational executive leadership function began to 
strengthen, but the professional leadership have declined. "Educators" in the practical work of the application of more legal policies, ignoring the legal knowledge of the training and education, while information technology training has been unable to meet the current needs of education and management development.

1.4 The Management Content of Management Decision-making Personnel. Educational decision-making belongs to the high-end behavior of education, can give education development and reform development and strategic plan. It is found that the feasibility, practicability and rationality of educational decision-making would affect the scientific and technological content of educational decision-making. Relate research shows that many educational management departments at the present blindly emphasize the implementation of education policy, but ignored the policy assessment, and it does not match the fact . Educational policy must be developed in accordance with factual data, while results-oriented, in the long-term development of continuous education reform, in order to achieve educational goals [2].

\section{The Educational Management Model on the Large Data}

Large data had a greater impact on the education management and it provides a new means of development, causing that education construction also has a large data characteristic.

2.1 Understand the Characteristics of Educational Management Data. First, large data has created a development of the management environment. Large data has replaced the traditional education asymmetry of the information relationship .And it had a great impact on the educational management decision-making environment . Based on the analysis of the environment, it is necessary to use not only the formation data but also the growth and variability education data and Xiyuan in education management. In this case, it has a great influence on the education management decision.

Second, the low density of large data has promoted educational management to the development of simple and professional [3]. The education management system not only has the function of storing the massive data, but also it is the core platform of data processing, which requires the management to construct the simple data model according to the management strategy and realize the management goal.

Third, the original and fast processing characteristics of the large data led the educational management has reflected the fragmentation characteristics. Educational management and educational activities is a synchronous process, the actual operation not only requires the education to provide real large data and results, but also with the timely processing of data, it is reflecting the debris of the behavior process of educational managers .

2.2 Build a Large Data Management Model. Western education management has been achieved the development from the "formal model", "college model" to "cultural model" , analyze the problem with a number of ways [4]. Many scholars in our country have also started to construct the "theoretical mode of thinking". In the future development, the main goal are to realize the essential change of educational management mode.

The formation of the educational management model requires large data support. The actual establishment mainly constructs the more complicated system with the main body of "subject", "resource" and "object" and "target", and uses the cloud technology to realize the education data processing, satisfies the majority of educational scholars' personalized needs on educational resources services, it is reflecting the educational resources characteristics with the fairness. Large data education management model is showed in Figure 1 below. 


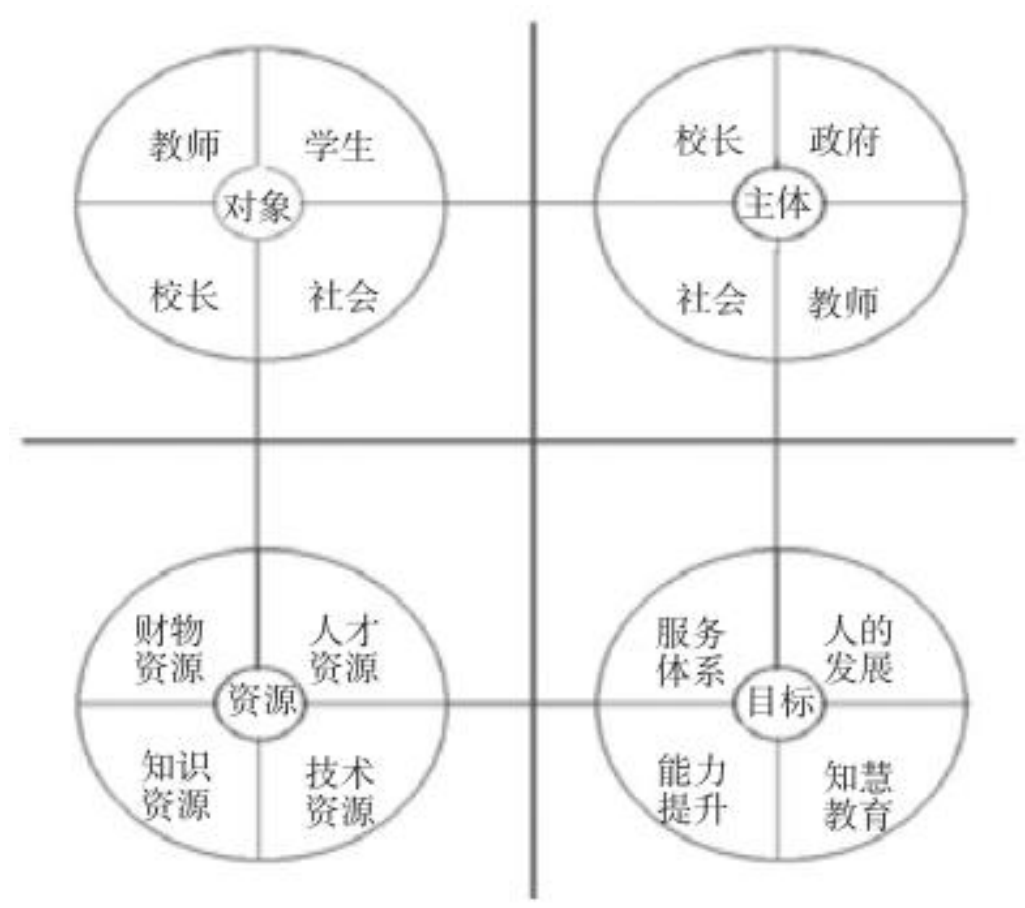

Figure 1 Large data education management model

In the era of large data, education managers have a strong professional and diversified characteristics, reflecting the professionalism and diversity characteristics of education. The diversification requirements of education system ,they are allowing social institutions to participate in education management, and take a certain educational activities; "principals" and "teachers" are the core of the management, excellent teachers manage school is the main sign of school-based management.

When education management is carried out, people are the important data for education and also the source of educational data. Human factors not only include the internal staff of education, but also involves many social people that can be used as educational data, it also is the large data education management in the larger data [5].

When allocate the educational resources, the first requirements are a reasonable classification, regarded the financial and materials as a basic resource; knowledge resources as a general resource, which are the fundamental resources and composed mainly by the educational content, methods, theory and experience, etc.; technical resources is the main data management resources, requires must be reasonably configured.

The main goal of the implementation of educational management are to build a modern education system with wisdom and provide people with the development of resources in order to achieve the equal allocation of educational resources; build a large data onto the education of public education system; improve the educational target and the management ability of data mining and utilization continuously, achieve the transformation of educational models, and promote the development of educational management to the direction of science.

\section{Realize the Roadmap for Managing Large Data Management}

Education data is a more systematic project, combined with the current level of education and information technology, in the future development of large education data it also need to experience a long development. So the education staff must overall develop from the ideological, theoretical and practical development, combined with the current situation to draw up a long-term development road map. As shown in Figure 2 below. 


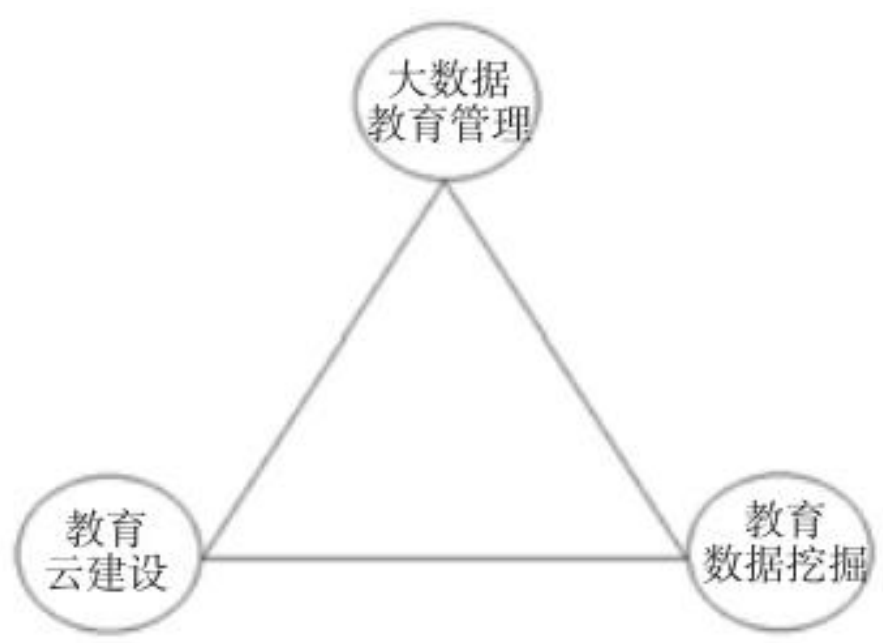

Figure 2 the roadmap for managing large data management

From the point of view of educational data management, the bottom is the technology of large data education management, which requires strengthen the cloud construction and construct the distributed educational data center (cloud) according to the national standard, which targets to form the construction that is organized by the resource pool, the data relation and the database , and strengthen the education of large data mining, statistics of education generated data timely; the high-level education management operating system needs to develop from the public service to students, in order to ensure that everyone has the right to receive quality education.

\section{Conclusion}

This paper mainly analyzes the change of education management mode in the era of large data. At the present stage, the rapid development of computer and network technology has laid a foundation for people to learn more about the big data. In order to promote the change of educational management mode in the era of large data, it is necessary to reform the view of data mining and large data, and strengthen the application of educational management theory, means, technology and culture.

\section{References}

[1] Xiao Feng.Research on the Reform Trend of University's Asset Management Model in the Data Age [J]. Finance and Accounting, 2015, (09).

[2] Chen Wen; Pu Qingping; Zou Fangming.Study on the Change of College Students' Educational Management Mode and the Countermeasures in the Big Data Age [J] .Jiangsu Higher Education, 2017, (01).

[3] Qu Yao. Big data age education management model reform [J]. China Management Information, 2016, (02).

[4] Zhao Hongxia. the Change of enterprise human resources management brought by the era of large data [J]. Modern state-owned enterprises, 2015, (02).

[5] Chen Haiying. Change and optimization of archives management mode in colleges and universities under the background of large data age [J]. Liaoning Economy, 2017, (01) 